\title{
Students Perception on the Level of Classroom Engagement at a Korean University
}

\author{
https://doi.org/10.3991/ijet.v14i20.11469
}

\author{
Shaneil R. Dipasupil ( $\bowtie)$, Hyun Jung Lee, Joung-Hyun Ham \\ Hanseo University, Seosan-si, South Korea \\ roshaneilal@gmail.com
}

\begin{abstract}
This research aims to provide valuable information to the professors and school officials among the higher education institutions in South Korea on the level of classroom engagement among undergraduate students. Questionnaires based on the literature review were administered to 500 students at a university in South Korea. Descriptive statistics, t-test, and ANOVA were used to analyze the data gathered. It was found out that student engagement is the highest in terms of behavioral indicators. Specifically, the responses showed that asking relevant questions during the class is the most frequent way to show that the students are engaged in the classroom. Furthermore, hypotheses, as regards the variance of responses when grouped according to the demographic variables of the respondents, were tested. It was found out that student engagement did not differ significantly in terms of the gender of the participants and their grade point average while the opposite is true in terms of the year level and their department. Furthermore, the most favored engagement strategies by the students include providing the purpose of the activity and assisting the students in completing the activity. This set of information would benefit the teachers and other school officials in creating a plan of action that is geared towards promoting better classroom engagement among students. Through a higher level of engagement, not only the students are learning more effectively, but also they are taking more ownership of their learning process, all of which positively contribute to improved student outcomes.
\end{abstract}

Keywords - Student Engagement, Student Outcome, Active Learning, Classroom Strategies

\section{Introduction}

The rising cost of education everywhere in the world has led to tremendous pressure of ensuring that the students are getting the best quality that the university has to offer. The intense worldwide competition for students has created a greater need for higher education institutions to develop curricula and educational policies that are geared toward improving rates of student retention and improving rates of academic success. One of the most viable strategies to achieve these goals is the development of student engagement strategies. Literature is replete with the strong positive correlation between student engagement and student outcomes. Student engagement has been 
identified as a predictor of high quality learning and teaching in higher education. Furthermore, the strong correlation between student engagement and student retention is widely accepted. However, establishing student engagement within the classroom is still one of the challenges that the teachers encounter. It is even more challenging to consider the very nature of student engagement which is dynamic and multi-faceted. There is no bulletproof approach to ensuring engagement among the students. However, the better we understand the nature and complexities of student engagement, the better are we to provide appropriate and meaningful interventions in order to promote student engagement.

This study is aimed to identify the levels of engagement in the classroom as perceived by the students themselves and what they think are the strategies that the teachers can do to further promote classroom engagement. The results of the study are deemed beneficial to teachers and other academic staff in designing strategies that are more appropriate and effective in promoting student engagement.

\section{$2 \quad$ Literature Review}

As stated in Ref. [1] there is an ever growing pressure to ensure more positive student outcomes due to increased competition among higher education institutions around the globe. These student outcomes may be in the form of higher GPAs, higher student retention rates or higher employability rates. However, as important as these student outcomes are the strategies and methodologies that the higher education institutions undertake in order to produce the desired results.

As indicated in Ref. [14], scholars agree that learning is greatly influenced by how a student participates in educationally purposeful activities. Students need to devote their time and effort to such activities that would enhance their learning experiences. Such time and effort is defined by Ref. [2] as student engagement. Student engagement has been a popular topic for research and academic discourse because of its established positive correlation to student outcomes. As shown in Ref. [4] students who were engaged during a class lecture performed better than those who were not engaged. There were several theories and models presented to better understand student engagement. One of these is the Generative Theory of Learning States which suggested that students learn better when they are highly engaged during the class as stated in Ref. [17]. The Theory of Involvement and the Theory on Quality of Effort were both predicated on the concept that students will gain greater college experience based on the time and effort they put in to their activities as discussed in Ref. [1, 15]. Still another model which sought to explain student engagement is the Application, Response, Collaboration Model otherwise known as ARC Model. It explained that the students should make connections, respond and reflect, and then collaborate with their peers. Furthermore, students should think through a topic individually, and then collaborate with their peers through small-group discussions, and then present their output to the whole class. According to Ref. [11], by using real-world examples to explain the concept that they studied would increase its meaning and impact to the learning process of the students. 
Based from the review of literature, there are four approaches to understand student engagement. First is the behavioral approach which includes the thinking processes and the behavior of the students. This approach also highlights the importance of effective teaching practices. According to Ref. [10], the behavioral approach includes elements such as a positive conduct and rule compliance, involvement in learning such as time on task and asking questions, and wider participation in extracurricular activities. This behavioral approach towards identifying and measuring student engagement has gained greater popularity among the academia as there is a shift in focus from attitudes and student opinions in favour of student behaviors. The second approach is the psychological one which highlights engagement as an internal individual process. The third approach is the socio-cultural approach which emphasizes the crucial role of the institutions of higher learning and the support activities that they offer. The fourth and last approach is the holistic approach which acknowledges the strengths of the other approaches and tried to bridge the approaches into an interdependent whole. Furthermore, the holistic approach considers the students' own motivations and expectations.

In order to measure student engagement, there are three main indicators that are widely recognized in literature. First is the behavioral engagement which is generally indicated by behaviors considered by the institution as positive. These include attendance, punctuality, compliance with assignment deadlines, and class participation. The second one is the emotional or affective engagement which is revealed in positive attitudes such as showing an authentic and sincere interest in the topic being discussed, generating a sense of belonging or having a general feeling of satisfaction about class time and university life. The third is the cognitive engagement which is about deep thinking and learning. Examples of this include the students' desire for more challenging tasks or the students' request for more conversations with the teachers in order to explore the topic further.

With respect to the strategies that the teachers can develop in order to promote better student engagement, research has shown as stated in Ref. [7] that student engagement can be stimulated when effective teaching methods are used. When a learnercentered environment is created, it can promote and further sustain student engagement as pointed out in Ref. [9]. According to Ref. [6], student engagement is enhanced when the instruction is designed in such a way that it stimulates collaboration among the students, provides timely and relevant feedback, encourages active learning, establishes high expectations, and acknowledges different ways of learning. Furthermore, teachers who use technology such as creating online assignment using web 2.0 technologies appeared to have better experiences in promoting student engagement as described in Ref. [5]. In addition, Ref. [3, 8] highlighted that students are more likely to engage if their teachers are engaged with them and with the teaching process. 


\section{Methodology / Materials}

The data for this study was obtained from undergraduate students at a University in South Korea, who belong to a range of academic majors and departments. Usable survey responses were completed by 500 students out of the 520 distributed equivalent to $96 \%$ of response rate. The survey questionnaire was adapted from Ref. [13]behavioral. The instrument was a 40-item questionnaire designed to identify the levels of engagement of students inside the classroom. The item questions were selected based on their relevance and measurability of student engagement at the classroom level. The survey instrument covered the demographic profile of the target respondents, and the student engagement in terms of behavioral, affective and cognitive indicators. Furthermore, questions about strategies that the teachers can do to promote engagement were also included. The data collection was employed in the beginning of Spring 2019 in one University in South Korea. An online survey was created and the link was sent to the students through the professors who showed the link to the class and advised the students to answer the survey before the class began. After the responses were collected, descriptive statistics such as frequencies and weighted means were used to analyse the data. Furthermore, t-tests as well as MANOVA were used to understand the differences of variables.

\section{$4 \quad$ Results and Findings}

\subsection{Demographic profile of the respondents.}

Table 1 shows the demographic characteristics of the respondents of the study.

Table 1. Demographic Profile of the Respondent

\begin{tabular}{|c|c|c|}
\hline Demographic Variables & Frequency & Percentage $(\%)$ \\
\hline \multicolumn{3}{|c|}{ Year Level } \\
\hline $1^{\text {st }}$ year & 268 & 53.60 \\
\hline $2^{\text {nd }}$ year & 218 & 43.60 \\
\hline $3^{\text {rd }}$ year & 9 & 1.80 \\
\hline $4^{\text {th }}$ year & 5 & 1.00 \\
\hline \multicolumn{3}{|c|}{ Sex } \\
\hline Male & 249 & 49.81 \\
\hline Female & 251 & 50.19 \\
\hline \multicolumn{3}{|c|}{ Department } \\
\hline Aeronautic Studies & 5 & 1.00 \\
\hline Comprehensive Aviation Studies & 172 & 34.40 \\
\hline Health Science & 205 & 41.00 \\
\hline Design \& Media Entertainment & 92 & 18.40 \\
\hline Sports & 12 & 2.40 \\
\hline Liberal Arts \& Interdisciplinary Studies & 14 & 2.80 \\
\hline \multicolumn{3}{|c|}{ Grade Point Average } \\
\hline $\mathrm{A} / \mathrm{A}+$ & 97 & 20.58 \\
\hline
\end{tabular}




\begin{tabular}{|l|c|c|}
\hline $\mathrm{B} / \mathrm{B}+$ & 206 & 41.54 \\
\hline $\mathrm{C} / \mathrm{C}+$ & 144 & 29.62 \\
\hline $\mathrm{D} / \mathrm{D}+/ \mathrm{F}$ & 33 & 8.27 \\
\hline Total & 500 & 100 \\
\hline
\end{tabular}

More than half of the respondents are freshmen, followed by the sophomores equivalent to $43.60 \%$. The remaining $2.80 \%$ are either juniors or seniors. There are more females than males who participated in the study, but only by a negligible difference. In terms of the department, majority of the respondents equivalent to $41 \%$ belong to the Health Science department followed by $34 \%$ from the Comprehensive Aviation Studies department. In terms of the grade point average, more than half of the respondents have at least B as their GPA while around 37\% of the respondents have $\mathrm{C}$ as their highest grade point average.

\subsection{Perception of the respondents as to their level of engagement}

Table 2 shows the student engagement in terms of the behavioral, affective and cognitive indicators.

Table 2. Perception of the Respondents to their Level of Engagement in terms of Behavioral Indicators

\begin{tabular}{|l|c|l|}
\hline \multicolumn{1}{|c|}{ Behavioral } & $\begin{array}{c}\text { Weighted } \\
\text { Mean }\end{array}$ & \multicolumn{1}{|c|}{ Verbal Interpretation } \\
\hline Asked relevant questions during class & 2.14 & Occasionally \\
\hline Contributed to class discussions by giving own insights on the topic & 2.52 & Often \\
\hline Paid full attention to the class and resist distraction & 2.48 & Occasionally \\
\hline Worked with classmates on assigned tasks during class time & 2.75 & Often \\
\hline Helped the other classmates learn the topic while in class & 2.45 & Occasionally \\
\hline Overall weighted mean & 2.47 & Occasionally \\
\hline
\end{tabular}

In terms of behavioral indicators, the highest weighted mean was attributed to the respondents who often worked with classmates on assigned tasks during class time followed by those who often contributed to class discussions by giving own insights on the topic, with weighted means of 2.75 and 2.52 respectively. On the other hand, the remaining indicators such as asking relevant questions during class, working with classmates outside of class to complete class assignments, and helping the other classmates learn the topic while in class on an occasional basis were done by the respondents on an occasional basis and generated weighted means of 2.48, 2.45 and 2.14 respectively. With 4 as the highest point in the Likert scale, it is implied that the students' perception on their level of engagement is somewhat in the middle of the continuum. This suggests that more can be done in order to elicit full engagement among the students during their class time. 
Table 3. Perception of the Respondents to their Level of Engagement in terms of Affective Indicators

\begin{tabular}{|l|c|l|}
\hline \multicolumn{1}{|c|}{ Affective } & Weighted Mean & Verbal Interpretation \\
\hline Interested in the content being presented & 2.28 & Occasionally \\
\hline Conscious about the grades and other performance metrics & 2.26 & Occasionally \\
\hline Thinking analytically or critically & 2.45 & Occasionally \\
\hline Completing the assigned tasks independently & 2.58 & Often \\
\hline Completing the assigned tasks with other students & 2.41 & Occasionally \\
\hline Overall weighted mean & 2.40 & Occasionally \\
\hline
\end{tabular}

Table 3 revealed that the respondents perceived that they often had completed the assigned tasks independently while their responses were perceived as occasionally engaged in terms of being interested in the content being presented, being conscious about the grades and other performance metrics, thinking analytically or critically, and completing the assigned tasks with other students. With an overall weighted mean of 2.40 , the respondents perceived that they are occasionally engaged in terms of the affective indicators. This goes to show that a lot has to be done in order to promote better student engagement, particularly in terms of the affective domain.

Table 4. Perception of the Respondents to their Level of Engagement in terms of Cognitive Indicators

\begin{tabular}{|l|c|l|}
\hline \multicolumn{1}{|c|}{ Cognitive } & $\begin{array}{c}\text { Weighted } \\
\text { Mean }\end{array}$ & $\begin{array}{c}\text { Verbal Inter- } \\
\text { pretation }\end{array}$ \\
\hline Memorizing facts and ideas from the lessons & 2.34 & Occasionally \\
\hline Analysing ideas, concepts and rules in depth & 2.27 & Occasionally \\
\hline Forming a new idea or understanding based from various sources of information & 2.22 & Occasionally \\
\hline Evaluating a point of view, conclusion or information source & 2.40 & Occasionally \\
\hline Applying concepts to real-world problems or to new situations & 1.76 & Occasionally \\
\hline Overall weighted mean & 2.20 & Occasionally \\
\hline
\end{tabular}

The results of Table 4 revealed that the respondents perceived to be occasionally engaged in all the cognitive indicators presented in the survey with an overall weighted mean of 2.20. Evaluating a point of view, conclusion or information source got the highest weighted mean of 2.40. Other indicators include memorizing facts and ideas from the lessons, analyzing ideas, concepts and rules in depth, forming a new idea or understanding based from various sources of information, and applying concepts to real-world problems or to new situations. The occasional engagement of the students as regards the cognitive indicators poses more challenges for the teachers in order to create a classroom set up that would evoke greater engagement among the students.

\subsection{Teacher Strategies Perceived as Useful to Promote Engagement.}

Table 5 shows the teaching strategies that the respondents perceive to be useful in order to promote student engagement. 
Table 5. Teacher Strategies Perceived as Useful to Promote Engagement

\begin{tabular}{|l|c|c|}
\hline \multicolumn{1}{|c|}{ Teacher Strategies Perceived as Useful to Promote Engagement } & Frequency & Rank \\
\hline Assist the students in completing the activity & 495 & 2 \\
\hline Provides the purpose or goal of the activity & 496 & 1 \\
\hline Creates a healthy competition among the class & 461 & 8 \\
\hline Shows that there is always room for improvement & 488 & 3 \\
\hline Gives the necessary materials and resources to complete the task & 485 & 4 \\
\hline Sets a time limit on the activity to encourage completion of tasks & 441 & 12 \\
\hline Makes student participation a part of the student grade & 477 & 5 \\
\hline Sets the rules for engagement & 463 & 6 \\
\hline Creates a storyline that would connect the lesson to daily life & 418 & 14 \\
\hline Asks the students how they like to participate & 408 & 15 \\
\hline Creates small group discussions & 313 & 18 \\
\hline Encourages teamwork among the students and allow students to answer together & 461 & 9 \\
\hline Allows the students to answer questions in their own way & 463 & 7 \\
\hline Uses games in teaching a lesson & 259 & 20 \\
\hline Uses group project-based activities & 305 & 19 \\
\hline Allows working in pairs & 452 & 10 \\
\hline Gives opportunities for in-class writing & 369 & 17 \\
\hline Uses technology to evoke interest and enthusiasm among the class & 398 & 16 \\
\hline Uses a variety of teaching methods & 425 & 13 \\
\hline Provides fun and interactive activities & 443 & 11 \\
\hline
\end{tabular}

In terms of the strategies that the teachers can adopt in order to promote engagement in the classroom, the provision of the purpose or goal of the activity has been the most frequently identified by the respondents as useful. This is parallel to the concept of the Identified Regulation Model which suggests that teachers can increase student engagement by providing the students with a rationale that they can identify with and is of use to them as pointed out in Ref. [12]. The second in rank is assisting the students in completing the activity. This is followed by the teacher showing and ensuring the students that they can still improve. These findings run parallel with the educational concept that when the students are given the rationale why they have to do an activity, and they take part in the goal setting, the students take ownership and are more empowered. Empowered students are seen to be more engaged and more accountable to their learning. By setting clear goals, teaching learning strategies, and encouraging students to believe in themselves, while stressing the importance of personal obligation contributed to predicting academic engagement, which predicted academic success.

Among the strategies presented, using games in teaching a lesson is identified by a little over than half of the respondents and is ranked the last. This is quite surprising to note considering that the use of games is one of the most popular methods to promote engagement. This may be due to the nature of the students and to the applicability of games to the lessons being taught. 


\subsection{Hypotheses testing}

Table 6. T-test Results

\begin{tabular}{|l|c|c|l|}
\hline Profile Variable: Gender & P value (t-test) & Significance level & \multicolumn{1}{c|}{ Decision } \\
\hline Behavioral level & 0.2902 & 0.05 & $\mathrm{H}_{\mathrm{o}}$ accepted \\
\hline Affective level & 0.00243 & 0.05 & $\mathrm{H}_{\mathrm{o}}$ rejected \\
\hline Cognitive level & 0.013358 & 0.05 & $\mathrm{H}_{\mathrm{o}}$ rejected \\
\hline
\end{tabular}

Based from the t-test results in Table 6, the null hypothesis is accepted in terms of the behavioral indicators of student engagement. This means that the perception of the respondents did not vary significantly when they were grouped according to gender. However, the reverse is true for both affective and cognitive indicators of engagement. The null hypotheses were rejected which means that the responses vary significantly when grouped according to gender.

Table 7. ANOVA Table

\begin{tabular}{|l|c|c|l|}
\hline \multicolumn{1}{|c|}{ Profile Variable: Year Level } & F value & Critical Value & \multicolumn{1}{c|}{ Decision } \\
\hline Behavioral level & 0.3889 & 3.0556 & $\mathrm{H}_{\mathrm{o}}$ accepted \\
\hline Affective level & 0.4525 & 3.0556 & $\mathrm{H}_{\mathrm{o}}$ accepted \\
\hline Cognitive level & 6.0849 & 3.0556 & $\mathrm{H}_{\mathrm{o}}$ rejected \\
\hline
\end{tabular}

The ANOVA results presented in Table 7 showed that the perceptions of the respondents did not vary significantly in terms of behavioral and affective indicators but showed significant difference in terms of cognitive indicators when responses were grouped according to year level.

Table 8. ANOVA Table

\begin{tabular}{|l|c|c|l|}
\hline \multicolumn{1}{|c|}{ Profile Variable: Department } & F value & Critical Value & \multicolumn{1}{c|}{ Decision } \\
\hline Behavioral level & 6.1302 & 2.7587 & $\mathrm{H}_{\mathrm{o}}$ rejected \\
\hline Affective level & 0.2386 & 2.7587 & $\mathrm{H}_{\mathrm{o}}$ accepted \\
\hline Cognitive level & 4.3587 & 2.7587 & $\mathrm{H}_{\mathrm{o}}$ rejected \\
\hline
\end{tabular}

The ANOVA results presented in Table 8 showed that the null hypotheses were rejected in terms of the behavioral and cognitive levels while the opposite is true in terms of the affective level when the responses were grouped according to the department. This means that the perception of the respondents did not vary significantly in terms of the affective indicators of engagement regardless of the department that they belong. However, there are significant differences in the responses in terms of the behavioral and cognitive levels when grouped according to department.

Table 9. ANOVA Table

\begin{tabular}{|l|c|c|l|}
\hline \multicolumn{1}{|c|}{ Profile Variable: GPA } & F value & Critical Value & \multicolumn{1}{c|}{ Decision } \\
\hline Behavioral level & 2.4625 & 3.0556 & $\mathrm{H}_{\mathrm{o}}$ accepted \\
\hline Affective level & 0.3797 & 3.0556 & $\mathrm{H}_{\mathrm{o}}$ accepted \\
\hline Cognitive level & 1.9848 & 3.0556 & $\mathrm{H}_{\mathrm{o}}$ accepted \\
\hline
\end{tabular}


The ANOVA test on the GPA shown in Table 9 revealed that there are no significant differences on the perceptions of the respondents to their levels of engagement in terms of behavioral, affective and cognitive when responses were grouped according to their grade point average. It has been noted that high levels of student engagement positively contributed to cumulative GPA and students' perception of their overall academic experience as stated in Ref. [16].

\section{$5 \quad$ Conclusion and Recommendations}

In this study, it is claimed that the perception of the students on their behavioral level of engagement only differ significantly when responses were grouped as to their department. In terms of the affective engagement, the perception of the respondents did not vary when grouped according to their profile variables except for gender. Finally, the cognitive level of engagement did not vary significantly only when grouped according to the grade point average.

In addition, this study suggests that there are certain strategies that the teachers can do in order to promote better engagement among the students. Among those perceived by the respondents as useful include giving the rationale for the activity and assisting the students to complete the activity. Other strategies highly preferred by the respondents include giving the necessary resources to complete the tasks and making participation as part of the grade. These preferred strategies by the respondents show the desire of the respondents to be guided and led by the teachers towards the completion of the activities during class time. Furthermore, these results evoke a typical observation about Korean students being highly conscious of their grades, and that their effort inside the classroom should contribute to their final marks.

Based from these conclusions, it is highly recommended that the professors in Korean Universities and other universities as well take a more proactive role in engaging their students during class time. Students in general are distracted with a lot of things inside and outside of class work. It is a greater challenge for the professors to design a coursework that would evoke interest and enthusiasm among the student to participate more and to invest more time and effort towards achieving educationally purposeful activities. Students participate more in a classroom and also report a better understanding of concepts when steps are taken to actively engage them. When the teacher is engaged, there is a greater likelihood that the students would also be engaged.

\section{References}

[1] Astin A. (1999). Student involvement: A developmental theory of higher education. Journal of College Student Development, 40(5), 518-529.

[2] Australian Council for Educational Research. (2010). Doing more for learning: Enhancing engagement and outcomes. Australasian Student Engagement Report. Camberwell: ACER.

[3] Bryson, C. and Hand, L. (2007). The role of engagement in inspiring teaching and learning. Innovations on Education and Teaching International, 44, 349-362. https://doi.org/10. $\underline{1080 / 14703290701602748}$ 
[4] Campbell, J. and Mayer, R. (2009). Questioning as an instructional method: Does it affect learning from lectures? Applied Cognitive Psychology, 23(6), 747-759. https://doi.org/10. $\underline{1002 / \mathrm{acp} .1513}$

[5] Chen, P.D., Lambert A.D. and Guidry K. (2010). Engaging online learners: The impact of web-based learning technology on college student engagement. Computers \& Education, 54(4), 1222-1232. https://doi.org/10.1016/j.compedu.2009.11.008

[6] Chickering, A. and Gamson, Z. (1987). Seven principles for good practice in undergraduate education. AAHE Bulletin, 39, 3-7.

[7] Collaco, C. (2017). Increasing student engagement in higher education. Journal of Higher Education Theory and Practice, 17(4).

[8] Delialioglu, D. (2012). Student engagement in blended learning environments with lecturebased and problem-based instructional approaches. Educational Technology and Society, 15(3), 310-322.

[9] Doyle, T. (2008). Helping students learn in a learner-centered environment: A guide to facilitating learning in higher education. Sterling, VA: Stylus Publishing.

[10] Fredericks, J,A., Blumenfield, P., and Paris, A. (2004). School engagement: Potential of the concept, state of the evidence. Review of Educational Research, 74, 59-109.

[11] Hourigan, K.L. (2013). Increasing student engagement in large classes: The ARC model of application, response and collaboration. Teaching Sociology, 41(4), 353-359. https://doi. org $/ 10.1177 / 0092055 \times 13491580$

[12] Jang, H. (2008). Supporting students' motivation, engagement and learning during an uninteresting activity. Journal of Educational Psychology, 100(4), 798-811. https://doi.org/10. $\underline{1037 / \mathrm{a} 0012841}$

[13] National Survey of Student Engagement (2000). Improving the college experience. Bloomington, IN: Indiana University Center for Postsecondary Research and Planning.

[14] Nygaard, C. (2013). Student engagement: Identity, motivation and community. Faringdon: Libri Publishing.

[15] Pace, C.R. (1982). Achievement and the quality of student effort. Paper presented at National Commission on Excellent in Education, Washington D.C.

[16] Webber, K.L., Krylow, R.B. and Zhang, Q. (2013). Does involvement really matter? Indicators of student college success and satisfaction. Journal of College Student Development, 54(6), 591-611. https://doi.org/10.1353/csd.2013.0090

[17] Wittrock, M. (1990). Generative processes of comprehension. Educational Psychologist, 24, 354-376.

\section{$7 \quad$ Authors}

Dr Shaneil Ramos-Dipasupil, Ph.D is an Assistant Professor of the Department of Liberal Arts \& Interdisciplinary Studies at Hanseo University teaching both undergraduate and graduate levels. She is also a researcher and consultant for various international NGOs, addressing key areas such as economic development, climate change, and management. She has presented her research studies in numerous international conferences and had published in international journals as well.

Hyun Jung Lee, Ed.D is an Assistant Professor of the Department of Liberal Arts \& Interdisciplinary Studies at Hanseo University. She graduated from Columbia University in NY, USA with Ed.D in Adult Education. 
Dr Joung-Hyun Ham, Ph.D is the Vice President of External Affairs and the Dean of Teaching Department at Hanseo University. She graduated from Bridgeport University in CT, USA with Ph.D in Educational Administration.

Article submitted 2019-05-25. Resubmitted 2019-07-05. Final acceptance 2019-07-20. Final version published as submitted by the authors. 